\title{
Corneal manifestations of selected systemic diseases: A review
}

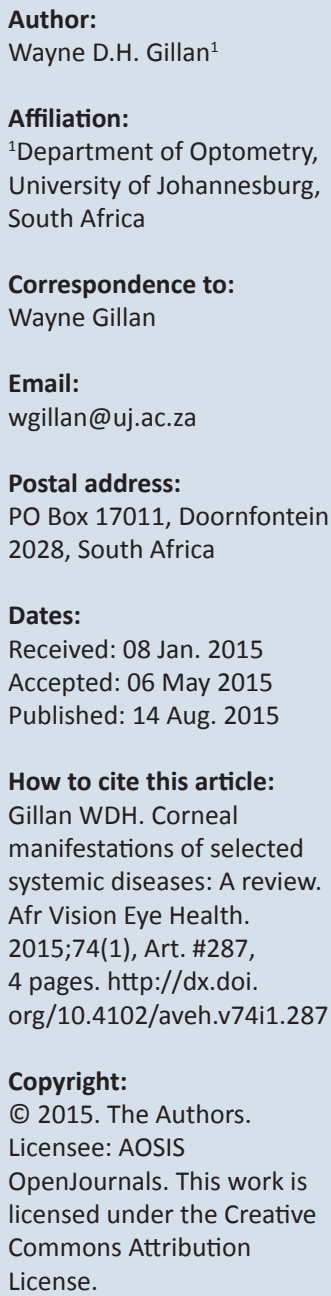

The corneal manifestations of several selected systemic diseases are reviewed. Metabolic, immunologic and inflammatory and infectious diseases are included. A brief overview of each disease and how it manifests in the cornea is discussed. The importance of conducting a slitlamp examination on every patient is emphasised.

\section{Introduction}

Many ocular signs may indicate (or be related to) underlying systemic disease. Examples of systemic diseases that may have ocular manifestations include diabetes, hypertension, thyroid disease, multiple sclerosis and myasthenia gravis, amongst many others. Corneal manifestations of systemic disease are numerous, therefore necessitating a biomicroscopic examination of the cornea during any visual examination conducted by an optometrist.

Corneal manifestations of systemic disease may be induced by numerous conditions including metabolic, immunologic, inflammatory and infectious processes. ${ }^{1}$ Abelson and Plumer ${ }^{2}$ emphasise the anatomical and physiological differences between the central and peripheral cornea and how the manner in which a disease manifests itself can be influenced by such differences in anatomy and physiology. The present article reviews selected systemic diseases and the corneal manifestations that may be associated with those diseases.

\section{Metabolic diseases}

Numerous metabolic diseases may result in corneal disorders or abnormalities that are manifestations of an accumulation of abnormal substances that can affect corneal transparency at the biomicroscopic or subjective visual level. ${ }^{3,4}$ The visual significance of many of the metabolically related corneal changes is variable. For example, the verticillate keratopathy induced by the use of amiodarone is usually innocuous whilst similar corneal changes associated with the chronic use of chloroquine are often accompanied by a vision-destroying maculopathy. ${ }^{3}$

Tyrosinemia II is a rare recessive oculocutaneous syndrome that usually manifests during the early months of life. ${ }^{3,5}$ The disease is associated with bilateral pseudodendritic keratitis (75\% of cases), palmoplantar hyperkeratotic lesions ( $80 \%$ of cases) and mental retardation $(60 \%$ of cases). ${ }^{5}$ Patients may present with ocular signs and symptoms including epiphora, photophobia, blepharospasm, corneal clouding, pseudodendritic and dendritic lesions and, rarely, corneal or conjunctival plaques. ${ }^{5,6}$ Recurring pseudodendritic keratitis may be the presenting sign of this disease (often treated extensively before the correct diagnosis is made ${ }^{5}$ ) which is important to diagnose early since a low-tyrosine, low-phenylalanine diet can be curative. ${ }^{3,5}$

Fabry's disease is an X-linked fat storage disorder owing to absent (or deficient) activity of lysosomal exoglycohydrolase. Fabry's disease is one of the lipidoses which also includes diseases such as Tay-Sachs disease, Niemann-Pick disease and Gaucher's disease..$^{1,3,7}$ Whilst ocular signs may include vascular abnormalities, cataract and vessel tortuosity, the most common, and most distinctive, ocular sign is corneal opacity. The corneal opacities associated with Fabry's disease are mostly found in the epithelial or sub-epithelial layers of the cornea and present, initially, as a diffuse haziness that progresses to the typical whorl-like corneal verticillata (whorl-like rays emanating from a single vortex). ${ }^{8}$ The radial lines are usually cream-coloured but may also range from white to golden-brown. ${ }^{8}$ Figure 1 shows the typical presentation of verticillata.

Cystinosis is a rare autosomal disease resulting in the accumulation of cystine within lysosomes, leading to intracellular cystine accumulations in the conjunctiva, cornea, iris, choroid and retinal pigment epithelium. ${ }^{3}$ In nephropathic cystinosis, intralysosomal cystine crystallises, resulting in the destruction of several tissues, including the kidney, thyroid, testis, pancreas, brain and eye..$^{910}$ Cystinosis can be classified as infantile, intermediate and adult, depending on the age of onset. ${ }^{3}$ 


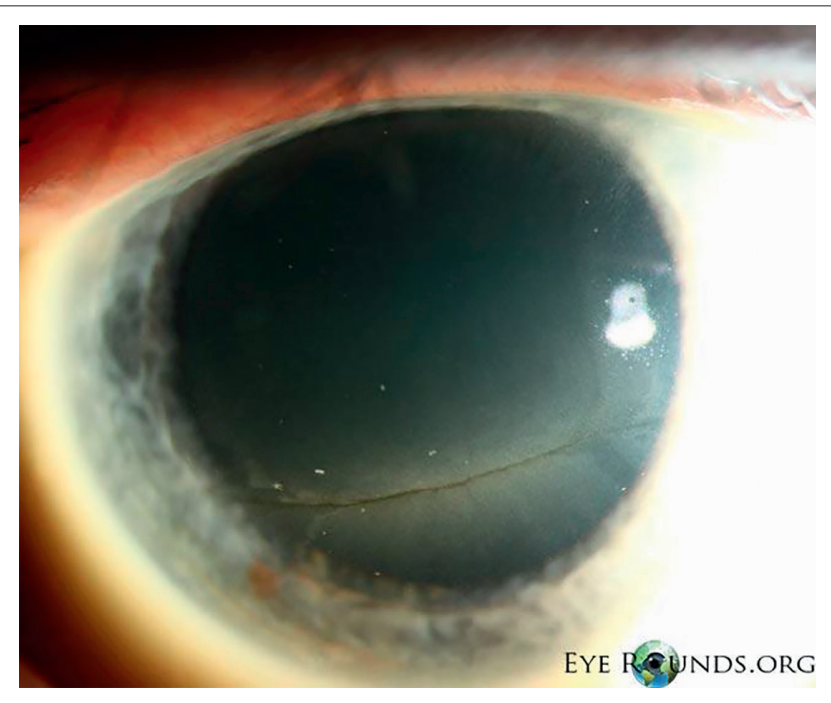

Source: Used with permission from http://www.eyerounds.org, University of lowa, USA FIGURE 1: Verticillata resulting from Fabry's disease.

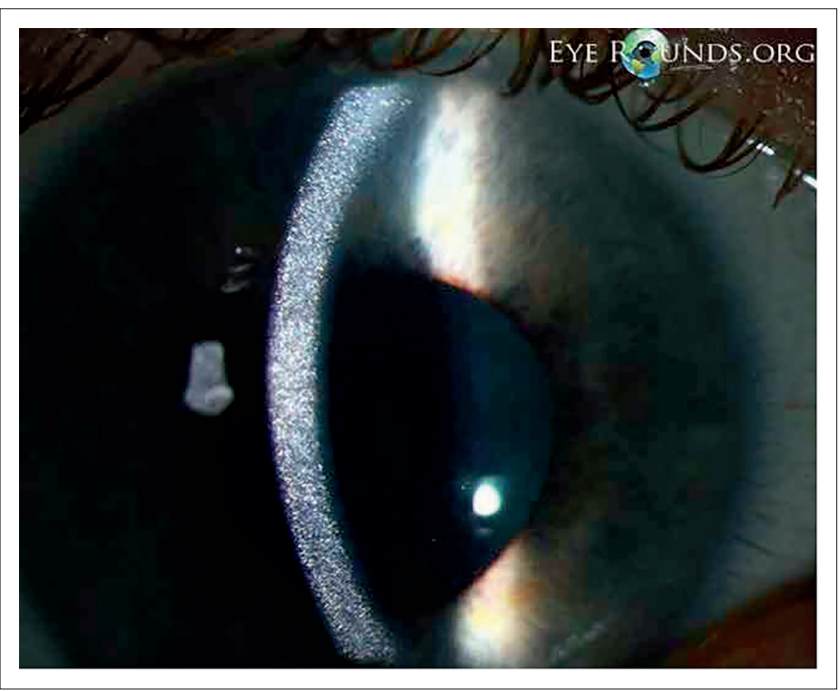

Source: Used with permission from http://www.eyerounds.org, University of lowa, USA FIGURE 2: Corneal crystalline changes observed in cystinosis.

In the cornea, cystine crystals are predominantly found in the anterior stroma, are iridescent and polychromatic, and needle-like in shape. ${ }^{3}$ Photophobia is a common symptom, and the predominantly anterior location of the crystals predisposes the cornea to recurrent erosion. ${ }^{3}$ Whilst the adult form of the disease is benign, requiring no treatment, the infantile form of the disease can be lethal. ${ }^{3}$ The resultant appearance of the cornea in cystinosis can be seen in Figure 2 .

Gout is characterised by the deposition of monosodium urate crystals into joints, commonly the joints of the big toe (caused by hyperuricaemia), and chronically, into other tissues such as heart valves, kidneys and perichondrial tissues, resulting in inflammatory foci known as tophi. ${ }^{11}$ The disease initially results in transient but recurrent attacks of acute arthritis. ${ }^{11}$ Gout may be classified as primary and secondary, with primary gout being a genetic disorder and the cause of approximately $90 \%$ of all cases of gout. ${ }^{12}$ Secondary gout is usually a manifestation of hyperuricemia that is secondary to other disorders (e.g. increased nucleic acid turnover, a high purine intake or excess alcohol consumption). ${ }^{12}$ The corneal manifestation of gout is the deposition of uric acid crystals into the nuclei of the epithelial cells and the superficial stroma where they appear as fine, punctate or needle-like, refractile crystals. ${ }^{12}$ The crystalline deposition is often confused with band keratopathy but the crystals associated with gout are often brownish whilst band keratopathy depositions are commonly whitish-grey in colour., ${ }^{3,12}$ The eye may become acutely inflamed in patients suffering from gout, giving rise to the 'hot eye of gout' ${ }^{\prime 13}$ as quoted by Kenyon et al. ${ }^{3}$ (original reference Hutchinson ${ }^{13}$ ).

Another metabolic disease that has corneal implications is Wilson's disease (hepatolenticular degeneration ${ }^{3}$ ), a rare hereditary, autosomal recessive disorder. ${ }^{4,14}$ Wilson's disease is characterised by a hepatic copper excretion disorder that results in copper accumulation in several tissues including the liver, kidneys, eyes and nervous system. ${ }^{14}$ A Kayser-Fleisher ring is the most commonly noted corneal manifestation of Wilson's disease. ${ }^{4,14}$ A Kayser-Fleischer ring is usually seen as a golden-brown (varying from golden-brown, green, yellow and bronze to reddish-brown) discoloration of Descemet's membrane near the limbus, ${ }^{3,14}$ and in its early stages is best seen by means of gonioscopy. ${ }^{3}$

\section{Immunologic or inflammatory disorders}

Another category of signs manifesting in the cornea results from inflammatory or immunologic systemic diseases. ${ }^{1}$ Immunologic differences are present between the central and peripheral cornea. ${ }^{15}$ The peripheral cornea, being closer to the limbus, has more Langerhans cells, IgM and more $\mathrm{C} 1$ (recognition unit of the complementary system) than the central cornea, meaning that antigen-antibody complexes may initiate the complement system more effectively than the central cornea. ${ }^{15}$ Ocular signs reflecting systemic immunologic or inflammatory disease often affect the cornea as well as the conjunctiva, and most of these patients are symptomatic from an ocular point of view as well. ${ }^{1}$

Patients presenting with unexplained orbital inflammatory disease, cicatricial conjunctivitis, scleritis, peripheral ulcerative keratitis, retinal vascular occlusion or, infrequently, uveitis, should be suspected of having Wegener's granulomatosis (WG). ${ }^{16,17}$ WG is a rare necrotising vasculitis characterised by acute necrotising granulomas, focal necrotising vasculitis and renal disease. ${ }^{11}$ Involvement of the eye occurs in approximately $40 \%$ of individuals with WG and might be the presenting manifestation of this disease. ${ }^{17}$ The corneal manifestations of WG include infiltrates (often associated with adjacent scleritis), interstitial keratitis and peripheral ulcerative keratitis. ${ }^{16}$

Rheumatoid arthritis (RA) is a 'chronic systemic inflammatory disease of unknown etiology' with the prominent feature being progressive deforming arthritis. ${ }^{11}$ Most commonly, keratoconjunctivitis sicca is the ocular disease associated 
with RA (approximately $15 \%$ - 25\% of patients). ${ }^{18}$ However, Messmer and Foster ${ }^{19}$ were of the opinion that the ocular disease most commonly associated with RA is peripheral ulcerative keratitis (PUK). PUK is a disease characterised by a crescent-shaped destructive inflammation of the cornea near the limbus that can be associated with epithelial defects, stromal infiltrates and progressive stromal degradation and thinning, ${ }^{15}$ and has a high risk of perforation. ${ }^{20}$ Jifi-Bahlool et al. ${ }^{21}$ state that the treatment of PUK is both local (to prevent scleromalacia and vision loss) and systemic (to prevent systemic vasculitis which can result in high mortality). $\mathrm{Kanski}^{4}$ supports this view and states: 'Severe, persistent, peripheral corneal infiltration, ulceration or thinning unexplained by coexistent ocular disease should therefore prompt a search for an associated systemic collagen vascular disorder which may be life-threatening'. A systemic disease commonly associated with RA is Sjögren's syndrome. ${ }^{22,23}$ Sjögren's syndrome is an autoimmune disease that targets the lacrimal and salivary glands in the beginning stages of the disease and is characterised by lymphocytic infiltration of exocrine glands resulting in absent or reduced glandular secretion. ${ }^{22,23}$ With the lacrimal and salivary glands being primarily affected, dry eye (keratoconjunctivitis sicca) and xerostomia are common conditions in patients suffering from Sjögren's syndrome. ${ }^{24}$ Dry eye is a common cause of filamentary keratitis which can also be associated with autoimmune collagen vascular diseases such as Sjögren's syndrome. ${ }^{1,25}$

Calcific band keratopathy (CBK) is considered to be a common condition that is caused by a calcific degeneration of the superficial layers of the cornea (specifically Bowman's membrane, the epithelial basement membrane and the anterior stroma). ${ }^{4}$ This degenerative condition is characterised by deposition of calcium resulting in whiteto-grey opacities in the superficial cornea and is usually found in the inter-palpebral zone of the cornea. CBK more

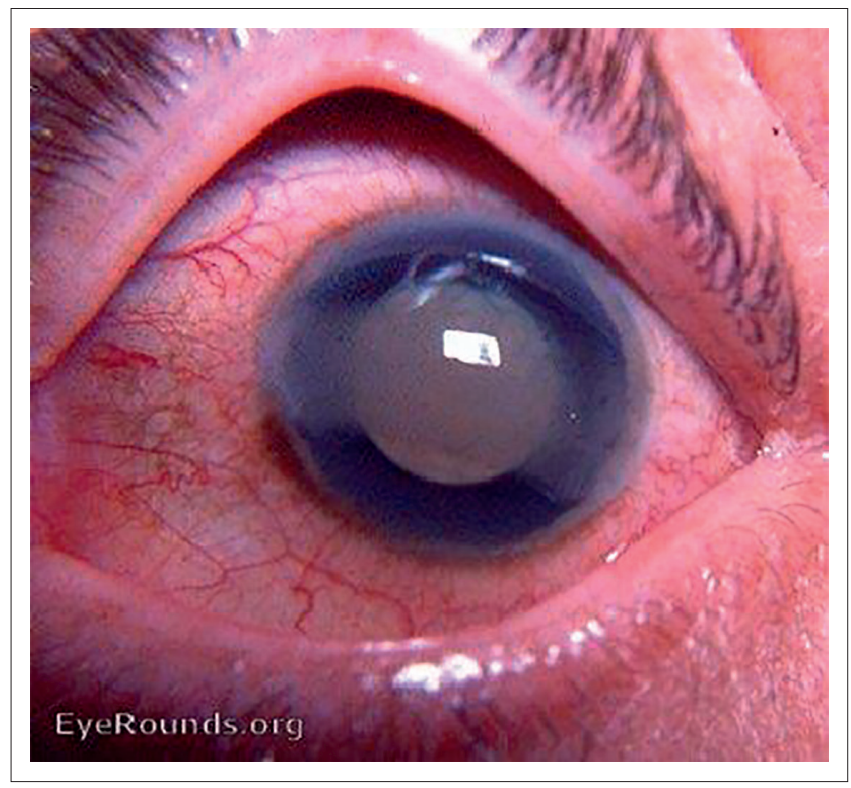

Source: Used with permission from http://www.eyerounds.org, University of lowa, USA FIGURE 3: Calcific deposition typical of band keratopathy. commonly starts in the corneal periphery at the 3 and 9 o'clock positions and has a lucent zone that separates the deposition zone from the limbus. ${ }^{1,26,27}$ However, chronic ocular inflammatory conditions can result in CBK starting in the central cornea. ${ }^{26}$ Numerous systemic conditions can be associated with $\mathrm{CBK},{ }^{26}$ examples being rheumatoid arthritis, Paget's disease, hyperparathyroidism and chronic renal failure, ${ }^{1,26,27}$ amongst others. Figure 3 shows a typical presentation of band keratopathy.

Theodore is considered to be the first person to describe the condition known as Superior limbic keratoconjunctivitis (SLK). ${ }^{28}$ The characteristics of this conditions are listed as: inflammation of the upper-lid tarsal and upper bulbar conjunctiva, staining of the adjacent cornea, superior limbic proliferation and filaments on the superior limbal area. ${ }^{28}$ The cause of SLK is considered unclear by some $e^{28}$ whilst others state that thyroid disease is the underlying causative mechanism, resulting in local mucin deficiency, abnormal friction of the upper conjunctiva and inflammation. . $^{129,30}$

\section{Infectious disease}

Several systemic infectious diseases can present with corneal manifestations. ${ }^{1}$ Interstitial keratitis (IK) is 'characterized by cellular infiltration and vascularization of the corneal stroma with minimal involvement of the corneal epithelium or endothelium' ${ }^{31}$ Interstitial keratitis can present with an acute as well as a non-acute phase with the presenting signs being different for the two presentations..$^{32}$ In the acute phase, the signs include vascularisation of the stroma, oedema, hyperaemia and even anterior chamber reaction. Non-acute signs include deep stromal haze, scarring, corneal thinning and ghost vessels in the stroma. ${ }^{32}$ Whilst IK most commonly occurs in the first to second decade of life, ${ }^{32}$ recent information suggests that adult onset of IK is becoming more common. ${ }^{33,34}$ With congenital syphilis being the most common cause of $\mathrm{IK}, 1,32$ other less common causes include acquired syphilis, tuberculosis, Cogan's disease, leprosy, herpes simplex and Lyme disease. ${ }^{32}$

Phlyctenulosis (or phlyctenular keratoconjunctivitis [PKC]) is a 'localized, noninfectious inflammatory process of the ocular surface'.$^{35}$ The presence of PKC is thought to represent a delayed hypersensitivity to some antigen - an antigen usually associated with bacteria, mycobacteria, a virus, and protozoan, fungal or parasitic organisms. ${ }^{35}$ Systemic diseases such as tuberculosis, Behçets disease, HIV and rosacea are commonly associated with PKC..$^{32}$ PKC can present with both corneal and conjunctival phlyctens. Usually, conjunctival phlyctens manifest as small nodules on the bulbar conjunctiva, are white in colour and are often found near the limbus. ${ }^{32}$ Corneal phlyctens also present as small, white nodules that often start at the limbus. Dilated conjunctival vessels are often found associated with the nodule. The nodule often migrates towards the centre of the cornea, resulting in a wedge-shaped neovascularised and scarred cornea. ${ }^{32}$ PKC is also considered to be one of the complications of eyelid margin (meibomitis) disease in young patients. ${ }^{36}$ 


\section{Conclusion}

Numerous systemic diseases manifest associated signs in the cornea. In some instances, the corneal changes might be the first indication that some, more serious, disease process underlies the corneal signs. Optometric practitioners need to be alert to the systemic diseases that may present with corneal manifestations.

\section{Acknowledgements Competing interests}

The author declares that he has no financial or personal relationships which may have inappropriately influenced him in writing this article.

\section{References}

1. Shovlin JP. Corneal manifestations of systemic disease. Rev Optom (Rev Corn Contact Lenses Supp). 2005; Jan/Feb:30-33.

2. Abelson MB, Plumer A. The two corneas. Rev Optom (Rev Corn Contact Lenses Supp). 2005;Jan/Feb:8.

3. Kenyon KR, Navon SE, Haritoglou C. Corneal manifestations of metabolic diseases. In: Krachmer JH, Mannis MJ, Holland EJ, editors. Cornea. 2nd ed. Philadelphia: Elsevier Mosby, 2005; p. 749-776.

4. Kanski JJ. Clinical ophthalmology: A systematic approach. London: ButterworthHeinemann; 2007.

5. Macsai MS, Schwartz TL, Hinkle D, Hummel MB, Mulhern MG, Rootman D. Tyrosinemia type II: Nine cases of ocular signs and symptoms. Am J Ophthalmol. 2001;132:522-527. http://dx.doi.org/10.1016/S0002-9394(01)01160-6

6. Tsai C-P, Lee N-C, Niu D-M, Lee S-M, Hsu W-M. Corneal lesions as the initial manifestation of tyrosinemia type II. J Chin Med Assoc. 2006;69:286-288. http:// dx.doi.org/10.1016/S1726-4901(09)70259-X

7. El-Abassi R, Singhal D, England JD. Fabry's disease. J Neurol Sci. 2014;344:5-19. http://dx.doi.org/10.1016/j.jns.2014.06.029

8. Samiy N. Ocular features of Fabry disease: Diagnosis of a treatable life-threatening disorder. Surv Ophthalmol. 2008;53:416-423. http://dx.doi.org/10.1016/ j.survophthal.2008.04.005

9. Gahl WA, Kuehl EM, Iwata F, Lindblad A, Kaiser-Kupfer MI. Corneal crystals in nephropathic cystinosis: Natural history and treatment with cysteamine eye drops. Mol Genet Metab. 2000;71:100-120. http://dx.doi.org/10.1006/ eye drops. Mol
mgme.2000.3062

10. Buchan B, Kay G, Heneghan A, Matthews KH, Cairns D. Gel formulations for treatment of the ophthalmic complications in cystinosis. Int J Pharm. 2010;392:192-197. http://dx.doi.org/10.1016/j.ijpharm.2010.03.065

11. Robbins SL, Cotran RS, Kumar V. Pathologic basis of disease. 3rd ed. London: WB Saunders, 1984; p. 1356-1362.

12. Burgos F, Capone RC. Ocular and systemic manifestations of gout. Clin Eye Vis Care. 1996;8:155-163. http://dx.doi.org/10.1016/0953-4431(96)00176-2

13. Hutchinson J. The relation of certain diseases of the eye to gout. $\mathrm{Br}$ Med J. 1884;2:995. http://dx.doi.org/10.1136/bmj.2.1247.995

14. Fenu M, Liggi M, Demelia E, Sorbello O, Civolani A, Demelia L. Kayser-Fleischer ring in Wilson's disease, a cohort study. Eur J Int Med. 2012;23:e150-e156. http:// dx.doi.org/10.1016/j.ejim.2012.04.005
15. Mondino BJ. Inflammatory disease of the peripheral cornea. Ophthalmol. 1988;95:463-472. http://dx.doi.org/10.1016/S0161-6420(88)33164-7

16. Tarabishy AB, Schulte M, Papaliodis GM, Hoffman GS. Wegener's granulomatosis: Clinical manifestations, differential diagnosis and management of ocular and systemic disease. Surv Ophthalmol. 2010;55:429-443. http://dx.doi. org/10.1016/j.survophthal.2009.12.003

17. McCluskey $P$, Powell $R$. The eye in systemic inflammatory disease. Lancet. 2004;364:2125-2133. http://dx.doi.org/10.1016/S0140-6736(04)17554-5

18. Conner MS, Brasington RD, Padousis AJL. Corneal disease in rheumatoid arthritis. In: Krachmer JH, Mannis MJ, Holland EJ, editors. Cornea. 2nd ed. Philadelphia: Elsevier-Mosby, 2005; pp. 1207-1224.

19. Messmer EM, Foster CS. Vasculitic peripheral ulcerative keratitis. Surv Ophthalmol. 1999;43:379-396. http://dx.doi.org/10.1016/S0039-6257(98)00051-4

20. Albert M, Beltrán E, Martínez-Costa L. Rituximab in rheumatoid arthritisassociated peripheral ulcerative keratitis. Arch Soc Esp Oftalmol. 2011;86:118120. http://dx.doi.org/10.1016/j.oftal.2011.01.003

21. Jifi-Bahlool H, Saadeh C, O'Connor J. Peripheral ulcerative keratitis in the setting of rheumatoid arthritis: Treatment with immunosuppressive therapy. Sem Arthr Rheum. 1995;25:67-73. http://dx.doi.org/10.1016/S0049-0172(95)80019-0

22. Price EJ, Vanables PJW. The etiopathogenesis of Sjögren's syndrome. Sem Arthr Rheum. 1995;25:117-133. http://dx.doi.org/10.1016/S0049-0172(95)80025-5

23. Nguyen $C Q$, Peck $A B$. Unraveling the pathophysiology of Sjögren syndrome associated dry eye disease. Oc Surf. 2009;7:11-27. http://dx.doi.org/10.1016/ S1542-0124(12)70289-6

24. Hamideh F, Prete PE. Ophthalmologic manifestations of rheumatic disease. Sem Arthr Rheum. 2001;30:217-241. http://dx.doi.org/10.1053/sarh.2001.16639

25. Diller R, Sant S. A case report and review of filamentary keratitis. Optom. 2005;76:30-36. http://dx.doi.org/10.1016/S1529-1839(05)70252-9

26. Chang RI, Ching SST. Corneal and conjunctival degenerations. In: Krachmer JH, Mannis MJ, Holland EJ, editors. Cornea. 2nd ed. Philadelphia: Elsevier Mosby, 2005; p. 987-1004.

27. Najjar DM, Cohen EJ, Rapuano CJ, Laibson PR. EDTA chelation for calcific band keratopathy: Results and long-term follow-up. Am J Ophthalmol. 2004;137:10561064. http://dx.doi.org/10.1016/j.ajo.2004.01.036

28. Driebe WT, Bhatia SS. Superior limbic keratoconjunctivitis. In: Krachmer JH, Mannis MJ, Holland EJ, editors. Cornea. 2nd ed. Philadelphia: Elsevier Mosby, 2005; p. 713-718.

29. Kadrmas EF, Bartley GB. Superior limbic keratoconjunctivitis: A prognostic sign for severe Grave's ophthalmopathy. Ophthalmol. 1995;102:1472-1475. http:// dx.doi.org/10.1016/S0161-6420(95)30843-3

30. Cher I. Clinical features of superior limbic keratoconjunctivitis in Australia: A probable association with thyrotoxicosis. Arch Ophthalmol. 1969;82:580-586. http://dx.doi.org/10.1001/archopht.1969.00990020582002

31. Whitcup SM, Smith JA. Non-syphilitic interstitial keratitis. In: Krachmer JH, Mannis MJ, Holland EJ, editors. Cornea. 2nd ed. Philadelphia: Elsevier Mosby, 2005; p. 1161-1168.

32. Kunimoto SM, Kanitkar KD, Makar MS, Friedberg MA, Rapuano MA, editors. Cornea. In: Wills eye manual: Office and emergency room diagnosis and treatment of eye disease. 4th ed. Philadelphia: Lippencott, Williams and Wilkins, 2004; e-book.

33. Wilhelmus KR, Jones DB. Adult-onset syphilitic stromal keratitis. Am J Ophthalmol. 2006;141:319-321. http://dx.doi.org/10.1016/j.ajo.2005.09.015

34. Dinis da Gama R, Cidade M. Interstitial keratitis as the initial expression of syphilitic reactivation. N Eng J Med. 2002;346:1799. http://dx.doi.org/10.1056/ NEJMicm010418

35. Mozayeni RM, Lam S. Phlytenular keratoconjunctivitis and marginal staphylococcal keratitis. In: Krachmer JH, Mannis MJ, Holland EJ, editors. Cornea. 2nd ed. Philadelphia: Elsevier Mosby, 2005; p. 1235-1240.

36. Suzuki T, Mitsuishi Y, Sano Y, Yokoi N, Kinnoshita S. Phlyctenular keratitis associated with meibomitis in young patients. Am J Ophthalmol. 2005;140:77-82. http:// dx.doi.org/10.1016/j.ajo.2005.02.039 